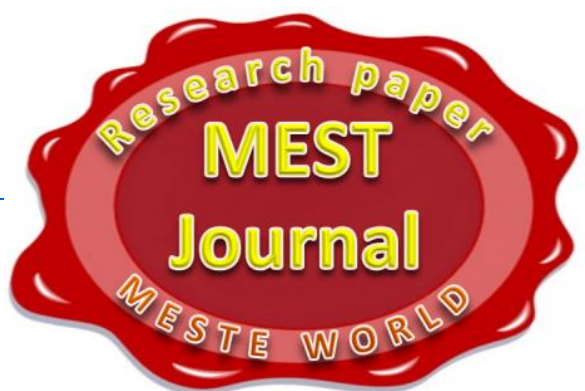

\title{
SYSTEM OF RANKING OF POSITIONS OF THE PERSONNEL AS A FACTOR OF AN ENTERPRISE ACTIVITY EFFICIENCY INCREASE
}

\section{Ekaterina Sidorenko}

Russian State University for the Humanities Domodedovo Branch, Domodedovo, Russia

\section{Mariya Ferafontova}

Russian State University for the Humanities Domodedovo Branch, Domodedovo, Russia

\section{(C) MESTE}

JEL Category: M12, 015

\begin{abstract}
Building any effective system of remuneration must begin with understanding what positions exist in the enterprise, how do they compare with each other, as one department can be compared with another division, i.e. construct a hierarchy of posts. This is achieved through evaluation and ranking of positions in the organization. The purpose of the evaluation system and ranking of posts is to establish a clear, understandable and manageable system of basic salaries. In the article, the system of ranking positions of the personnel is described. The algorithm for implementing a system of ranking at the company is suggested. Different types of ranks are described. Principles of grading and advantages of implementation of grading system on the enterprise are analyzed.
\end{abstract}

Keywords: system, positions ranking, algorithm, implementation, vertical rank, horizontal rank, principles of grading, labor market

\section{INTRODUCTION}

Building any effective system of remuneration must begin with understanding what positions exist in the enterprise, how do they compare with each other, as one department can be compared with another division, i.e. construct a hierarchy of posts. This is achieved through evaluation and

The address of the corresponding author: Ekaterina Sidorenko

㭋 esid-137@yandex.ru ranking of positions in the organization. The purpose of the evaluation system and ranking of posts is to establish a clear, understandable and manageable system of basic salaries. (Samoukina, 2003)

Rating and ranking of posts give the opportunity to make the wage system objective; transparent, clear; managed.

A full and reasoned analysis of positions from which to start building the system of evaluation and ranking also allows defining the requirements 
for core competencies and performance indicators. These levels will help in the analysis already established in the organization wages; in understanding the training and development of employees and motivating them to high labour productivity; optimization of company expenses for payment of labour; in developing the requirements for the vacant posts of the enterprise and, consequently, will increase the efficiency of enterprise management. The effectiveness of the system of ranking positions allows you to create an optimal system of material and moral motivation of personnel, efficient and productive labor to ensure the effectiveness of the company and increase of its competitiveness.

The job evaluation is now an integral part of the remuneration system. Its main advantage is the ability to translate this intangible indicator, as the value of the work of the employee in a cash equivalent. (Skovpen, 2008)

To evaluate positions, the grading is used. Grading - a grouping of posts on certain grounds (the definition of "weight", classification etc.) for the purpose of standardization of wages in the organization, because money is a way to determine the value of this position to the company. In fact, grading is a way of charging the building and system levels.

Grade (band or grade) is the minimum unit of distinction from the point of view of payment. This means that posts that fall in one grade, the difference in pay is insignificant, how small is the difference of their "weights" or grades. The range of pay for posts at the same grade can be called a tariff. It can be divided into pay grades - a minimum unit of discernment of payment for posts.

Grading solves the following tasks:

- ranking of works of importance to the organization;

- billing (definition of wages) on the basis of the importance of a specific job or position for the organization. It allows you to pay not only the market value of the employee but the importance of his work for the company. Billing is a career tool, and method of cost planning and personnel organization. Because the grades are combined they are similar in content and different hierarchical level of the post, it gives you the opportunity to "bind" to different grades in different levels of additional financial and non-financial incentives: differences in the scope and content of the social packages, benefits for different categories of employees, etc.

- motivation. For this to be a career running motivation for job candidates - the motivation of attraction. For example, in the enterprise, which is engaged in programming and intellectual development, for managers will be a grade of IT staff as the main earning and profitable, and only then will host the grade servants (lawyers, managers, etc.) (Travin \& Dyatlov, 2008)

Primarily, this system is convenient for large and medium-sized enterprises because, unlike the vertical arrangement of career, it allows you to build a career horizontally, within their own level.

\section{THE ALGORITHM FOR RANKING POSTS AT THE COMPANY}

The system of ranking positions began to be implemented in large enterprises in 2005-2006, when the grades were assigned empirically, practically in the absence of a technique of ranking.

An algorithm for its implementation is presented in figure 1. (Chemekov \& Kuznetsova, 2002)

Currently, the job evaluation is considered as a process definition, assignment and change the grade of the post. The grade is treated as a digital value, which indicates the degree of importance of the position.

Consider the basic concepts of posts that are present in large holding structures.

Matrix post is a typical post formed within the same methodological line Manager to perform all or part of the uniform functions assigned to this position.

Unique position - a full-time position, which has no methodical leader. Private position - a full-time position, which is not unique.

The definition of the consolidated rank of a matrix, and a private office. Consolidated rank matrix post /private posts is a numerical indicator representing a combination of vertical and horizontal forks of ranks specified in the format $X_{1}-Y$, where $X$ is the vertical grade, $Y$ - grade horizontal. 
The consolidated rank of private posts is determined on the basis of the composite rank of the matrix positions. The combined rank of the matrix positions is determined by calculation. The basis of determining the vertical rank is job assessment on three General parameters:
- the management level;
- communications;
- security clearance.

There are three types of ranks, they are presented in Table 1.

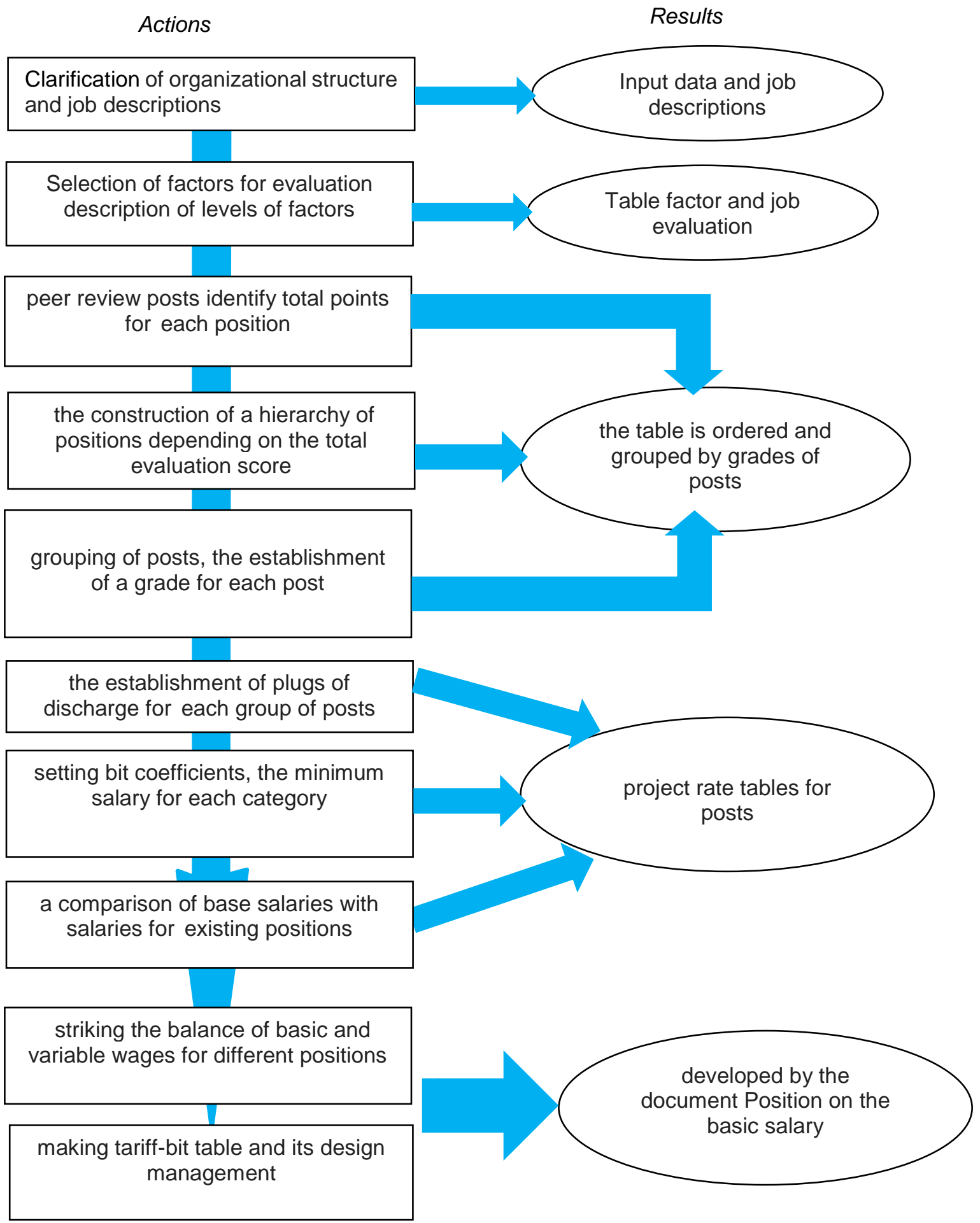

Fig. 1. The algorithm for implementing a system of ranking positions at the company. 
Table 1 The types of ranks in the enterprise

\begin{tabular}{|c|l|}
\hline The types of ranks & Definition \\
\hline Vertical rank & $\begin{array}{l}\text { A numeric indicator that represents important characteristics of the position: } \\
\text { management level, level of tolerance, the nature of internal and external } \\
\text { communication }\end{array}$ \\
\hline Horizontal rank & $\begin{array}{l}\text { A numeric indicator that identifies opportunities for professional growth, an } \\
\text { employee in the position. When the appointment is assigned rank 0. To assign } \\
\text { the next grade must receive training and successfully pass the test }\end{array}$ \\
\hline Consolidated rank & $\begin{array}{l}\text { A numerical indicator representing a combination of horizontal and vertical } \\
\text { grades, specified in the format } X Y, \text { where } X \text { is the vertical grade, } Y \text { - grade } \\
\text { horizontal }\end{array}$ \\
\hline
\end{tabular}

Table 2 Levels of management and the respective weight

\begin{tabular}{|c|l|c|}
\hline & Management level & weight \\
\hline 1 & Administrative management (absent) & 0 \\
\hline 2 & Administrative management of the department & 3 \\
\hline 3 & Administrative management of the enterprise & 7 \\
\hline 4 & Administrative management of few enterprises & 8 \\
\hline 5 & Operational management of private posts within the enterprise & 1 \\
\hline 6 & Operational management of private posts within few enterprises & 2 \\
\hline 7 & Project management & 1 \\
\hline
\end{tabular}

Table 3 Weight of internal communications at the enterprise

\begin{tabular}{|l|c|}
\hline The nature of internal communications within the main activity & weight \\
\hline $\begin{array}{l}\text { Communication implies the absence of the need for frequent (more than } 50 \% \text { of the } \\
\text { time) contact with the staff from other units }\end{array}$ & 0 \\
\hline $\begin{array}{l}\text { Communication involves frequent (more than } 50 \% \text { of the time) contacts for standard } \\
\text { algorithms }\end{array}$ & 3 \\
\hline $\begin{array}{l}\text { Communication implies the absence of the need for frequent (more than } 50 \% \text { of the } \\
\text { time) of contacts in problem situations or in the absence of the standard algorithms }\end{array}$ & 7 \\
\hline
\end{tabular}

Table 4 Determination of the object of external communications

\begin{tabular}{|c|c|c|c|c|}
\hline Object & $\begin{array}{c}1 \text { - interested } \\
\text { in contact }\end{array}$ & $\begin{array}{c}2 \\
\text { neutrals } \\
\end{array}$ & $\begin{array}{l}3 \text { - is not defined } \\
\text { or is not interested }\end{array}$ & $\begin{array}{c}4 \text { - set for } \\
\text { confrontation }\end{array}$ \\
\hline $\begin{array}{ll}\text { A. Providing the necessary } \\
\text { information }\end{array}$ & 0 & 1 & $x$ & $x$ \\
\hline $\begin{array}{l}\text { B. The information exchange } \\
\text { mutually beneficial cooperation }\end{array}$ & 1 & 1 & 2 & $x$ \\
\hline $\begin{array}{l}\text { C. Providing targeted exposure } \\
\text { within the framework of the } \\
\text { standard algorithms }\end{array}$ & 1 & 2 & 2 & 3 \\
\hline $\begin{array}{l}\text { D. The provision of purposeful } \\
\text { influence in problem situations }\end{array}$ & 2 & 2 & 3 & 4 \\
\hline
\end{tabular}

The management levels and their weight are shown in table 2. (DME, 2016)

The communications' nature allocates internal and external communications. Outcome indicator is a numeric value that is obtained by adding the totals by internal and external communications. Internal communications also assigned a weight, as shown in table 3. (DME, 2016)
The value of external communication is based on the combination of two parameters of the proposed installation of the object of external communications and the prevailing nature of the interaction with the object of external communications. This option is subject to assessment if the implementation of external communications represents more than $20 \%$ of the 
time. In other cases, this parameter is equal to zero.

Determination of the object's external communications is shown in table 4. (DME, 2016)

The security clearance is the third parameter that affects the grade of the post. The value of this parameter is determined by selecting from table 5 . (DME, 2016)

Table 5 The value of the security clearance

\begin{tabular}{|c|c|c|c|c|}
\hline $\begin{array}{c}\text { Security } \\
\text { clearance }\end{array}$ & First & Second & Third & Fourth \\
\hline Weight & 3 & 3 & 2 & 2 \\
\hline
\end{tabular}

Received in three weights are added, forming a vertical grade of the post. When forming ranks must comply with the following requirement: vertical position matrix rank cannot be greater than or equal to the vertical rank of the position's immediate administrative supervisor.

After determining the vertical grade of each post is assigned a horizontal grade. The value of the horizontal rank matrix positions does not depend on the vertical position and rank is determined at the discretion of the head of this methodological matrix positions. The maximum horizontal grade is 3. Minimum horizontal rank of 1 .

The consolidated rank of private posts is determined on the basis of a consolidated Matrix of rank positions and is set to posts. For private posts:

- not involving administrative leadership, consolidated the rank of private positions should be equal to half the rank of the matrix positions:

- involving the administrative implementation of the guide unit, the value of the vertical grade in the combined grade can be more or less parameter

than 1 , except for the private posts, correlated with the matrix.

The consolidated rank of private positions, which correspond to two or more of the matrix, is determined as follows: based on the consolidated ranks of each matrix position that is included in private, private are determined by the combined grades. Then select the maximum composite grade.

The number of horizontal grades of private positions is equal to the number of ranks matrix of the horizontal position. When assigning an employee to a position/transfer of an employee from a position horizontal grade is set different to 0.

For the number of posts is set imputed consolidated grade. For unique posts are special values of the composite rank.

The horizontal assignment of the grade is for appointment to a post at the desire of the employee to initiate the assignment of a second or third horizontal rank.

The process of assigning the composite grade assumes that the initiator of a process is:

- methodical Director for matrix positions;

- administrative lead for a unique position (because of unique posts there is no methodological guidance).

The rank calculation is made automatically, then there is a necessary clearance, is created and inserted into the system file with the calculation of the grade, then the document shall be approved by the leadership. Then there is the reflection of a consolidated grade card in the post and only after that HR-manager within three days changes the rank.

An example of the rank calculation is shown in Table 6.

Table 6 Example of calculating rank

\begin{tabular}{|c|c|c|c|c|c|c|}
\hline $\begin{array}{c}\text { The } \\
\text { managem } \\
\text { ent level }\end{array}$ & $\begin{array}{c}\text { the nature of } \\
\text { internal } \\
\text { communications }\end{array}$ & $\begin{array}{c}\text { the nature of } \\
\text { external } \\
\text { communications }\end{array}$ & $\begin{array}{c}\text { Security } \\
\text { clearance }\end{array}$ & $\begin{array}{c}\text { Vertical } \\
\text { rank }\end{array}$ & $\begin{array}{c}\text { Horizontal } \\
\text { rank }\end{array}$ & $\begin{array}{c}\text { Consolidated } \\
\text { rank }\end{array}$ \\
\hline 3 & 3 & 3 & 4 & 13 & 3 & 13.3 \\
\hline
\end{tabular}

Vertical and consolidated rank is calculated automatically.

The system of ranking positions of the staff found its use in the wage system. 
When calculating the salary, use the following formula:

$$
\begin{aligned}
& S^{\prime}=S^{*} H \\
& H=h\left(r_{0}+1\right){ }^{*} h\left(r_{0}+2\right){ }^{*} \ldots{ }^{*} h r_{1} . \\
& h=1.04(2<r<20)(\text { for transfers increase with } \\
& \quad \text { the grade to } 01 / 02 / 13) ; \\
& h=1.10(2<r<9) ; \\
& h=1.15(10<r<14) ; \\
& h=1.20(15<r<20) \text { (for transfers increase } \\
& \quad \text { with grade, ranging from } 01 / 02 / 13) ;
\end{aligned}
$$

$\mathrm{S}^{\prime}$ - $\quad \mathrm{CH}$ employee after the transfer;

$\mathrm{S}$ - $\quad \mathrm{CH}$ current employee prior to the transfer;

$r$ - grade vertical position;

$r_{0}$ - the vertical grade of the position from which the employee transferred on a current basis;

$r_{1}$ - the vertical grade of the position for which the employee is transferred on a current basis.

The formula for calculation of total salaries using time limits:

- individual form generation: using the same type of work, using several types of work;

- collective form generation: using the same type of work, using several types of work.

The use of collective forms is allowed only if the use of individual forms is impossible by the nature of the function performed by the wage.

Salary depends on the vertical rank: the higher the rank, the more salary. The horizontal grade is not taken into account.

\section{THE ALGORITHM FOR GRADING IN THE COMPANY}

Once all positions in the enterprise are described, they are grouped. In the future, assesses, and on the basis of assigned grades. The purpose of this procedure is the appointment of a fair and competitive remuneration. For this purpose, the results are not only internal evaluation but also labour-market data. For these purposes, it is proposed to use nationwide surveys. It is necessary to clear the entire staff into categories and assign each of them a position in the market in accordance with the data of external research, including salary survey.
Sources of information for analysis must be:

- job descriptions of employees;

- consultation with managers or educational leaders.

To optimize the system of ranking positions of the company, personnel must take the following steps:

1. Development of complete package of documents regulating the implementation of proposals for optimization of the system of ranking positions, including the basic concept.

2. The formation of the Expert group on preparation of offers on optimization of the system of ranking positions. Explanation and study of all of its members with the methods.

3. The ongoing job evaluation and their functionality. Involving representatives of these positions, conducting interviews with them, preparation of questionnaires, etc.

4. The requirements for various posts. Clarification of the factors.

5. Ranking of factors by levels.

6. The score of each level.

7. Evaluation weight factors.

8. The calculation of the number of points for each post.

9. The distribution of scores according to grades.

10. The establishment of salaries and calculation of tax "brackets".

11. Analysis of the results.

Best results can be obtained with the introduction in the enterprise is not only the practice of the use of grades but also supplement the system of key indicators of efficiency indicators of the rank of positions which will help optimally balance the ratio between constant and variable part of wages of the employee. The optimal ratio between fixed and variable part for most employees is $60 \%$ first and $40 \%$ second.

However, the optimization of grading system at the enterprise is not finished. After analyzing all of the options presented in the industry market compensation, management has a certain way to position the company, i.e. to decide whether the salary is average, below or above the average level. This takes into account strategic business objectives and financial resources.

With all these indicators is the development of the salary system. For each position, it is determined 
by the "fork" - the minimum and maximum amount of salary depending on the value of work of the employee and other factors.
Principles of grading can be applied in the system of awarding and assigning the benefits and the development of other motivation tools.

The possible positioning of the enterprise in the labor market is presented in Table 7.

Table 7 Positioning of company on wages

\begin{tabular}{|c|c|c|}
\hline \multicolumn{3}{|c|}{ Management } \\
\hline Top management & $\begin{array}{l}\text { middle management (heads } \\
\text { of departments) }\end{array}$ & $\begin{array}{l}\text { Junior management } \\
\text { (supervisors, team leaders }\end{array}$ \\
\hline $\begin{array}{l}\text { 1st year - } 15 \% \text { higher than the } \\
\text { average on the labor market; } \\
\text { 2nd year - } 20 \% \text { higher than the } \\
\text { average on the labor market; } \\
\text { 3rd year - } 25 \% \text { higher than the } \\
\text { average on the labor market }\end{array}$ & $\begin{array}{l}\text { 1st year - } 10 \% \text { higher than } \\
\text { the average on the labor } \\
\text { market; } \\
\text { 2nd year - } 15 \% \text { higher than } \\
\text { the average on the labor } \\
\text { market; }\end{array}$ & $\begin{array}{l}\text { 1st year - } 10 \% \text { higher than the } \\
\text { average on the labor market; } \\
\text { 2nd year - } 15 \% \text { higher than the } \\
\text { average on the labor market; }\end{array}$ \\
\hline \multicolumn{3}{|c|}{ Staff } \\
\hline The core staff & Administrative staff & Support staff \\
\hline managers of main activity & $\begin{array}{l}\text { Financiers, economists, } \\
\text { accountants, secretaries, etc. }\end{array}$ & $\begin{array}{l}\text { Janitors, cleaners, drivers, } \\
\text { storekeepers, etc. }\end{array}$ \\
\hline $\begin{array}{l}\text { 1st year - average labor market; } \\
\text { 2nd year - } 10 \% \text { higher than the } \\
\text { average on the labor market }\end{array}$ & $\begin{array}{l}\text { 1st year - average labor } \\
\text { market; } \\
\text { 2nd year - } 10 \% \text { higher than } \\
\text { the average on the labor } \\
\text { market }\end{array}$ & $\begin{array}{l}\text { Depending on financial } \\
\text { possibilities of the company } \\
\text { Market values are not very } \\
\text { important }\end{array}$ \\
\hline
\end{tabular}

The final decision about the positioning of enterprise on the labor market was adopted with the approved strategy of remuneration and the results of the internal analysis.

Further, it is advisable to develop a methodology of analysis posts. It is proposed to use a scoring method on key factors. The essence of this methodology is that experts (members of the Expert project group) are defined by a number of factors, all of which are qualities common to the work to be assessed. Each factor is assigned a "weight". Then each position is analyzed relative to the selected factors. The purpose of the analysis is to assess the work performed in specific positions, not specific employees.

\section{Analysis rules post:}

- the position must be analyzed in the form in which it is defined currently, and not as it was in the past or are planned in the future;

- work should be analyzed without regard to the level of its payment.
Using numerical methods of analysis are determined by the evaluation criteria, and each is assigned a "weight".

System levels will allow:

- to establish adequate remuneration and social packages for all the existing posts;

- to optimize the planning and control of personnel costs (recruitment, training etc.);

- to establish rules, standards and procedures for different level;

- to improve organizational culture based on the principles of industrial justice.

One of the problems identified in the analysis is the low number of criteria used when ranking posts at the company, which does not allow grades to fulfill their motivational functions. It is therefore proposed that the increase in the number of ranking criteria.

As key factors of job evaluation are proposed to use: 
- the nature of the work;

- responsible for the financial result;

- independence in work;

- experience;

- the level of special knowledge (qualification);

- the level of contacts (communication with clients);

- the difficulty of work (mental effort);

- the cost of failure;

- conditions of work;

- physical effort;

- the degree of influence on achieving the company's goals;

- value for the profession, taking into account, including its scarcity in the market.

The important point here is that proposed as a criterion to introduce such parameter as the risk of decisions (price errors). It is necessary to estimate the position and the cost of losing this position to the company.

However, you must pay attention to the following. Criteria can be objective or subjective. For an example, management level - objective, nature of communication is subjective. To minimize the influence of subjective criteria, it is necessary to reduce the weight of such criteria. It is advisable to reduce the number of subjective criteria to a minimum. To this end, we propose the establishment of a panel. An important issue is the composition of this Expert group and its functioning.

Each criterion is assessed a certain number of points. The total amount received by all criteria scores determines the value of each particular position for the company. Depending on the number of points a specific position falls within a particular interval - refers to a specific grade.

Grade $A$. In this grade there are posts senior executives and professionals responsible for developing the company's strategy, corporate policies, new programs, business plans. Work in these positions involves solving complex problems, characterized by a high degree of independence and responsibility.

Grade $B$. In this grade there are the positions of managers and specialists of medium level. Work in these positions makes high demands on management skills, professional knowledge, and personal qualities. It involves a high degree of communicativeness, responsibility, and creativity.

Grade $C$. In this grade there are the posts that make up the backbone of the company. Working in these positions are not initially imposes high requirements, but it is expected that in the normal course of business, employees must acquire special knowledge, abilities, and skills. This work is heavily regulated.

Grade $D$. In this grade there are support roles. Work in these positions is a simple, single-type operations and requires only basic skills.

In the optimization system of ranking positions can experience various difficulties.

Difficulties associated with the introduction of grades, can be classified on the same principle, and purpose that they can be used to solve it:

1. Personnel: the problem of the perception of the staff of the new system. This problem is directly related to managerial reasons, namely the poor organization of work on the project, lack of education among workers, reluctance to answer questions, policy management method.

2. Management:

- difficulty in withdrawal from the assessment of individual employees in favor of the assessment office;

- various errors based on incorrect subjective opinion, an unwillingness to look at things soberly, the desire to embellish;

- the desire to save money and still get all three constraints at once: cheap, fast and qualitatively.

3. Financial:

- lack of financing of the project;

- $\quad$ the inability to bring the real situation with wages that will be generated and defined as a result of the project.

Through mismanagement work on the project becomes a reality a wide range of problems. At best, improper work on the project can get a costly package that doesn't work, at worst you lose one or more key employees and simply not to withstand the pressure of competitors. With proper management of the work of the problem, most likely, will also appear, but they will be associated with the formation of the so-called "surviving" of 
the enterprise and its staff in the new regulations. The result is that the organization will receive significant additional growth potential.

Conduct grading with the help of consultants will help to avoid unforeseen problems and to construct logical and fair positions matrix. Also for the successful implementation of grades system are encouraged to inform the staff about the project. Awareness builds confidence and the lack of information rumors.

To maintain a remuneration system based on grades to date requires regular "upgrade" system. It is proposed to check the adequacy of the system once a year: on the one hand, it allows to release from the control of important changes both within the enterprise and in the labor market, on the other hand, this frequency does not allow to change it beyond recognition.

Adjustments can be both soft and hard. The soft adjustments system changes include changing the weights of compensable factors. For example, earlier it was important to focus on such factor as the "labor contents", but after the unification of certain activities, the emphasis may shift, for example, "work experience". Hard ways to adjust systems usually include changing the number or content of the factors, the scale of severity of individual factors. In this case, we have to reassess all positions and professions according to the new factors. It's already almost complete recycling system.

To adjust the model to yield the following events:

1. The new position, which must undergo the same assessment procedure as all positions and professions in the company and assigned to a particular grade.

2. The change in the market value of individual professionals - due to the opening of new competing companies in the region, or massive layoffs, an excess or a deficiency of graduates, etc. It is better to do it at the expense of introduction of allowances being transferred to employees on the contract or revise the accountant part.

The alteration of the contents or scope of work for the profession.

Tasks that can be solved by means of optimization of grading in the enterprise:
1. Personnel:

- The elimination of the state enterprise "lazy" employees who are accustomed not to earn money, and get.

- Understanding the business processes of an enterprise, and, consequently, improving employee engagement. Grading makes the atmosphere at the company is transparent and clear. This affects the involvement of employees in achieving common goals, and according to research, the profits of companies with a high level of employee engagement is 2.5 times higher than the competition.

- Increase the level of motivation as a consequence of the previous factor.

- Obtaining a convenient instrument for determining the base salary of the newly introduced positions.

- Comparison of the level of payments of the enterprise with the market average and bringing it to a competitive level.

- Determination of the mechanism and the size of bonuses or penalties.

- The employee gets a clear understanding of the possibilities of its development in the company, and, in most cases, ceases to feel undervalued.

- The grading system can become the locomotive of improving the professional level of the personnel.

- Increasing the attractiveness of HRbrand. Candidates when choosing an employer more and more interested in the existence of a grading on a par with having health insurance, career opportunities, etc.

2. Management:

- Optimization of the management structure. Grading helps to optimize the organizational structure.

- Elimination of duplicate functions.

- Integration of various units in holding structures.

- Improving the investment attractiveness and transparency.

3. Financial:

- Optimization of expenditure of the wage Fund by $20 \%$ on average. Through the creation of a compensation system based on the grading system, optimization of 
staff costs, resulting in savings of 10 to $50 \%$.

- Tools to track personnel costs.

- Determining the value of each position to the company.

\section{CONCLUSION}

Optimization of the system of ranking positions of the staff will increase motivation, allow employees, increasing their skills, get a promotion and pay levels. When properly built the enterprise the system of grading will increase the weight of the knowledge of the employee, and his salary will increase accordingly. In this position, it can remain the same.

For the employee of the enterprise optimization of the grade system will allow:

- $\quad$ to understand the place that takes its position in an existing hierarchy of positions and to evaluate its role for the company;

- to get a fair remuneration - depending on complexity, responsibility, etc. the work to be performed;
- to assess the prospects of their professional and career growth;

- get the opportunity to "horizontal" career development (promotion of the steps in one post due to the complexity of tasks, responsibility, and authority) - change of grade or undergrad and associated salary level;

- consistently acquire new professional knowledge and skills required to work effectively at a higher position.

In addition, the implementation of the proposed measures at the enterprise will allow achieving significant social outcomes:

- reduce employee turnover, because it assumes growth in the level of labor motivation of personnel;

- to raise qualification of the personnel of the enterprise;

- strengthen the corporate culture of the company and the commitment of employees to the enterprise.

\section{WORKS CITED}

Chemekov, V., \& Kuznetsova, T. (2002). Ranzhirovaniye - sredstvo upravleniya razvitiyem personala. Personal MIKS(3), 28-31.

DME. (2016). Internal documents of the Moscow Domodedovo airport. Moscow: Domodedovo Airport.

Samoukina, N. (2003). Upravleniye personalom: zarubezhnyy opyt. Sankt-Peterburg: Piter.

Skovpen, V. (2008). Greyding, ili differentsiatsiya zarabotnoy platy rabotnikov. Kadrovik(6), 11-22.

Travin, V., \& Dyatlov, V. (2008). Menedzhment personala predpriyatiya. Uchebno-prakticheskoye posobiye. Moscow: Delo.

Received for publication:

Revision received:

15.03.2016

Accepted for publication:

21.08.2016

12.12 .2016

\section{How to cite this article?}

Style - APA Sixth Edition:

Sidorenko, E., \& Ferafontova, M. (2017, Jan 15). System of ranking positions of the personnel as a factor of an enterprise activity efficiency increase. (Z. Cekerevac, Ed.) MEST Journal, 5(1), 94104. doi:10.12709/mest.05.95.01.12 
Style - Chicago Sixteenth Edition:

Sidorenko, Ekaterina, and Mariya Ferafontova. "System of ranking positions of the personnel as a factor of an enterprise activity efficiency increase." Edited by Zoran Cekerevac. MEST Journal (MESTE) 5, no. 1 (Jan 2017): 94-104. doi:10.12709/mest.05.05.01.12

Style - GOST Name Sort:

Sidorenko Ekaterina and Ferafontova Mariya System of ranking positions of the personnel as a factor of an enterprise activity efficiency increase [Journal] // MEST Journal / ed. Cekerevac Zoran. - Belgrade - Toronto : MESTE, Jan 15, 2017. - 1 : Vol. 5. - pp. 94-104.

Style - Harvard Anglia:

Sidorenko, E. \& Ferafontova, M., 2017. System of ranking positions of the personnel as a factor of an enterprise activity efficiency increase. MEST Journal, 15 Jan, 5(1), pp. 94-104.

Style - ISO 690 Numerical Reference:

System of ranking positions of the personnel as a factor of an enterprise activity efficiency increase.

Sidorenko, Ekaterina and Ferafontova, Mariya. [ed.] Zoran Cekerevac. 1, Belgrade - Toronto: MESTE, Jan 15, 2017, MEST Journal, Vol. 5, pp. 94-104. 